\title{
Investigation of the influence of multiple gasoline direct injections on macroscopic spray quantities at different boundary conditions by means of visualization techniques
}

\author{
D Martin, P Pischke, and R Kneer* \\ Institute of Heat and Mass Transfer, RWTH Aachen University, Aachen, Germany
}

The manuscript was accepted after revision for publication on 13 September 2010.

DOI: $10.1243 / 14680874 J E R 525$

\begin{abstract}
The reduction of combustion emissions and fuel consumption can be achieved by controlling the fuel mixture to be burned and therefore the fuel injection. In this study a gasoline direct injection (GDI) piezo hollow cone injector is investigated by visualization measurements. Both single and double injection events are examined in a pressurized chamber. For the single injection, the influence of the ambient temperature and pressure is analysed in detail. For the double injection, the ambient conditions and the time interval between two injections are varied.

For the single injection, the general shape of the spray, the recirculation eddy formed at the spray edge, the stringy structure of the hollow cone, and defined quantities such as the penetration length or the spray width are examined with respect to the influence of the ambient conditions. For the double injection, the same properties are evaluated, with the focus put not only on the influence of the ambient conditions, but also on the mutual interaction of two spray events.

The experimental results show a clear impact of both the ambient conditions and the time difference between two injections. In particular, the investigation of the recirculation eddy may be helpful in determining possible positions for the spark plug, since the spark plug is preferably placed in regions where the air-fuel mixture variations are minimal.
\end{abstract}

Keywords: gasoline direct injection (GDI), visualization, injection process, multiple injection, spray-spray interaction

\section{INTRODUCTION}

The demand for highly efficient combustion engines currently drives the development of new combustion concepts. One approach is the low-temperature combustion process, which promises high conversion efficiencies at low emission levels of $\mathrm{NO}_{x}$ and soot, while bearing the risk of combustion instabilities and misfiring. These instabilities may be suppressed by adequate control strategies such as multiple injections, providing the combustion process with a

*Corresponding author: Institute of Heat and Mass Transfer, RWTH Aachen University, Eilfschornsteinstraße 18, Aachen, 52062, Germany.

email: kneer@wsa.rwth-aachen.de temporally and spatially well-adjusted mixture of fuel and air.

Misfiring is prevented by reliably providing an ignitable mixture near the spark plug, with low deviations of the spray from cycle to cycle. These requirements may be met best by spray-guided injection strategies.

In the current paper, both single and double injections are investigated within a heated pressure chamber at steady-state chamber conditions. A visualization technique is used to characterize the influence of the chamber conditions and of double injections on macroscopic spray properties, such as the spray shape. The focus is placed on the mutual interaction between the first and the second injections, investigating how the mixture formation of the 
first injection may be manipulated by a second injection, and how the spray of the second injection is influenced by the residual fuel mixture and velocity field of the first injection. These investigations will help to gain further knowledge about the controllability of low-temperature combustion processes.

\section{STATE OF THE ART}

Other authors [1] have already mentioned the high potential of spray-guided injection processes. Besides appropriate air guidance, repeatable injections and accurate control of the injection process are crucial to provide an ignitable mixture within the ignition zone near the spray border in a reliable way. Thus Schwarz et al. [2] postulate the requirement of a spray cone which is independent of chamber conditions and is not influenced by charge motion. In this context, Béard [3] points out that control of the fuel-air mixture close to the spark plug is an important issue in direct-injection engines.

One injector often investigated in the context of spray-guided multiple injection applications is a piezoinjector developed by Siemens VDO and continued by Continental. In general, piezo-injectors are known for their outstanding dynamic properties. The delays for opening and closing of the nozzle are extremely short, enabling sequential injection pulses within short intervals [2]. The time for an entire opening and closing event (full lift) is only around $200 \mu \mathrm{s}$ [4].

The Continental piezo-injector features an outwardly opening nozzle, producing a wide-angle hollow cone spray. To make use of this spray geometry, the injector is mounted in the centre of the cylinder head close to the spark plug [5]. As a general feature, the cone shows a large number of 'strings' distributed around the circumference, which are very reproducible from one injection event to the other. Also, strong recirculation eddies at the inner and outer spray edge (see Fig. 1) can be found. Both the strings and the recirculation eddies have been investigated in the past.

The origin of the strings is the subject of several publications [6-9]. According to the investigations of

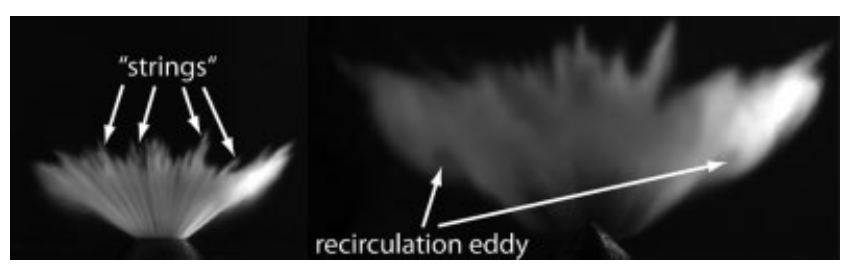

Fig. 1 Shape of the spray cone
Gavaises et al. [6], the strings are influenced, but not caused by, cavitation, as they are formed under noncavitating conditions as well. Comparing string formation in cavitating and non-cavitating conditions, it turns out that cavitating nozzles create thicker strings than non-cavitating nozzles. Further research published by Reckers et al. [7] finds that the nozzle design has a major influence on the string structure. Experiments and simulations show that the strings are caused by flow separation in the nozzle. Additionally, Befrui et al. [8] reveal that the string structure is caused by irregular wetting of the nozzle, and Nouri et al. [9] show that the string spacing is independent of Weber and Reynolds numbers, which supports the assumption that the strings are formed by air entrainment directly at the nozzle opening. Based on this approach, Nouri et al. [9] state that an imbalance between the dynamic forces of the liquid jet, the surface tension forces at the phase boundary, and the aerodynamic forces on the liquid film is responsible for string formation. Investigating the stability and the form of the strings, Nouri et al. [10] mention the good reproducibility of the string location. The chamber pressure has no major influence on the string structure; only the gap between the strings narrows with increasing gas pressure and density, as both promote droplet deceleration. In contrast, the injection pressure has significant influence [9] on the distance between the strings, which increases with the injection pressure. The needle lift has no effect on string formation.

The recirculation eddy at the spray edge has been investigated by various authors before. According to Zigan et al. [1], Béard [3], and Hermann et al. [11], the eddy consists of small droplets which follow the gas motion. It is found to be stable for all conditions examined by Zigan et al. [1]. As the recirculation zone is stable in shape and consists of smaller droplets, it is the preferred point of ignition, and crucial for a reliable ignition and stable combustion. Therefore, the location of the eddy must be investigated in detail to guarantee the correct positioning of the spray relative to the spark plug. Investigating the influences on the eddy so far, Francesco et al. [12] state that only cavitation has an influence on the eddy.

The influence of chamber conditions on spray formation has been investigated by some authors in detail. Most statements focus on the influence of the chamber pressure; temperature effects are not discussed. Nouri et al. [10] report no pressure influence on the spray cone angle. The effect of chamber pressure variations on the penetration length and spray geometry is treated briefly by Zigan et al. [1] and 
Schmid et al. [13]. In general, the penetration length decreases with increasing pressure. The lower penetration length affects the evaporation process, as the liquid spray is distributed across a smaller volume. The increase in vapour concentration restricts the vaporization process.

The application of the double injections is mentioned briefly by Schwarz et al. [2] and Warncke et al. [4]. The first injection produces an ignitable spray, while the second injection stabilizes the mixture formation [2]. A comparison of the emissions of single and double injections reveals a reduction in soot formation once double injections are applied [4].

Previous investigations have only briefly revealed the dependency of the spray shape on the time of injection during the engine cycle, and thus on the gas state within the cylinder/pressure chamber. Since the reliable prediction of the injection outcome is one prerequisite for accurate combustion control, the prediction of the spray shape has not so far been sufficiently investigated. No broad comparison between pressure and temperature influences has been published, nor has the impact of multiple injections on the spray shape been resolved in detail to date. Therefore, the correlations between the influencing parameters (chamber pressure and temperature, injection timing) and the spray properties must be investigated in detail. This will be presented in the current paper.

\section{EXPERIMENTAL SET-UP}

\subsection{Description of the test rig}

The major parts of the experimental set-up are a gasoline injection system, a heated pressure cham- ber of constant volume, and a visualization measurement set-up. In contrast to standard injection systems, the test injector is not fed by a supply pump, but pressurized by a nitrogen accumulator up to fuel pressures of $10 \mathrm{MPa}$. The fuel injected is a binary mixture of 95 per cent by volume (vol. \%) isooctane and 5 vol. $\% n$-heptane. This is commonly referred to as 'primary reference fuel' 95 (PRF 95).

The test injector is the Continental piezo-injector for homogeneous engine operation which has been described before. It is energized for full needle lift by a modified engine control unit (ECU) that is triggered by a transistor-transistor logic (TTL) signal externally energizing the first and the second injections for $300 \mu$ s each.

The experiments are conducted within a pressurized chamber, which is supplied with purge air of the desired conditions (pressure and temperature) at a velocity of $0.1 \mathrm{~m} / \mathrm{s}$ approximately. The pressure chamber has three quartz glass windows for optical access as illustrated in Fig. 2. The injector is mounted centrally in the chamber head, with the spray axis aligned to the chamber axis.

A scattered light measurement technique is used to visualize the liquid phase of the spray, i.e. the spray is illuminated by a stroboscope from the side, and the light scattered from the droplets is received by a charge-coupled device (CCD) camera. The arrangement of the stroboscope, the CCD camera, and the injector is shown in Fig. 3.

\subsection{Measurement procedure}

Contrary to high-speed camera measurements, the visualization measurements reported here take one single shot per injection. To observe the temporal

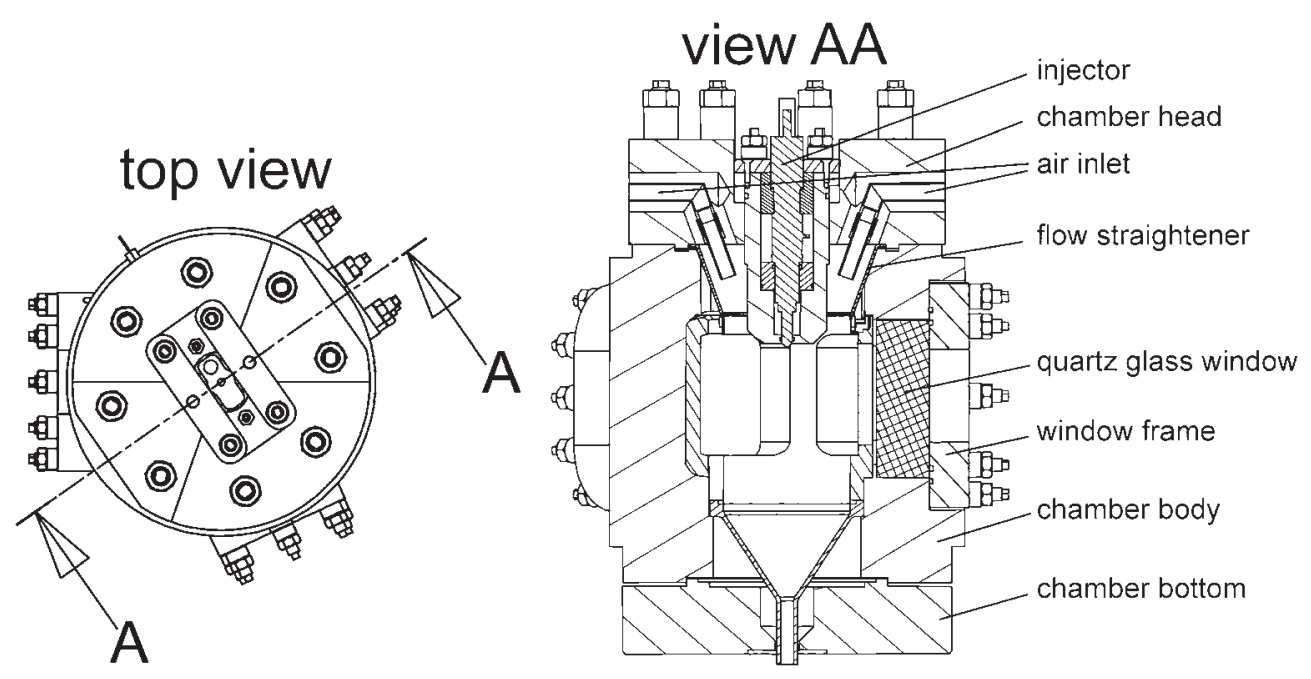

Fig. 2 Technical drawing of the pressurized chamber 


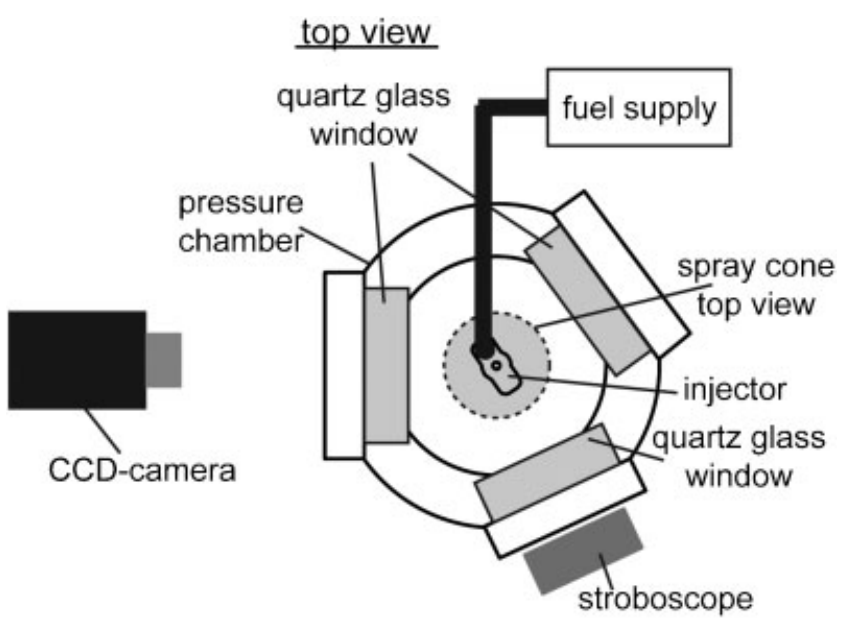

Fig. 3 Experimental set-up

development of the spray, measurements are taken from different spray events at different times after the start of injection. For each delay, 20 images are captured in repetition intervals of $2 \mathrm{~s}$ each, which are averaged after acquisition.

The conditions investigated are listed in Table 1. Single injections are marked ' $\mathrm{X}$ ', double injections are labelled ' $\mathrm{O}$ '. The injection intervals $\Delta t$ between the first and second injection of the double injection are $\Delta t=100 \mu \mathrm{s}, 150 \mu \mathrm{s}, 200 \mu \mathrm{s}, 300 \mu \mathrm{s}, 400 \mu \mathrm{s}, 600 \mu \mathrm{s}$, $800 \mu \mathrm{s}, 1000 \mu \mathrm{s}, 1200 \mu \mathrm{s}, 1700 \mu \mathrm{s}, 2200 \mu \mathrm{s}, 2700 \mu \mathrm{s}$, $3200 \mu \mathrm{s}$, and $3700 \mu \mathrm{s}$. For the smallest injection interval $\Delta t=100 \mu$ s no closing of the nozzle can be observed. At injection intervals of $\Delta t=150 \mu$ s or $200 \mu$ s the nozzle closes between two injection events; however, there is still a residual charge of the first injection when the second injection is started. Therefore, the measurements focus on intervals of $\Delta t \geqslant 300 \mu \mathrm{s}$. Expressed in terms of crank angle at $2000 \mathrm{r} / \mathrm{min}$, an injection interval of $\Delta t=100 \mu \mathrm{s} \mathrm{repre-}$ sents a crank angle of $1.2^{\circ}$, summing up to $44.4^{\circ}$ crank angle at $3700 \mu \mathrm{s}$. The trigger scheme of the double injection is illustrated in Fig. 4.

\subsection{Influence of purge air}

Owing to the low velocity of the purge air and the short measurement time, the influence of the purge air velocity may be neglected. At measurement times of $6 \mathrm{~ms}$, the air moves as little as $0.6 \mathrm{~mm}$. In turn, considering the repetition interval of $2 \mathrm{~s}$, the unburned fuel will move $200 \mathrm{~mm}$ in between two injections, which is enough to purge the chamber of any residues. Therefore, the air velocity is fast enough

Table 1 Ambient conditions investigated: X represents single injection, $\mathrm{O}$ represents double injection

\begin{tabular}{lllllll}
\hline & & \multicolumn{5}{c}{ Air pressure in the pressure chamber (MPa) } \\
\cline { 3 - 7 } & & 0.3 & 0.4 & 0.5 & 0.7 & 1.0 \\
\hline Air temperature in the pressure chamber $(\mathrm{K})$ & 300 & $\mathrm{X}, \mathrm{O}$ & $\mathrm{X}$ & $\mathrm{X}, \mathrm{O}$ & $\mathrm{X}$ & - \\
& 400 & - & $\mathrm{X}$ & $\mathrm{X}$ & $\mathrm{X}$ & - \\
& 450 & - & $\mathrm{X}$ & $\mathrm{X}$ & $\mathrm{X}$ & $\mathrm{X}$ \\
& 500 & - & $\mathrm{X}$ & $\mathrm{X}, \mathrm{O}$ & $\mathrm{X}$ & $\mathrm{X}, \mathrm{O}$ \\
& 550 & - & - & $\mathrm{X}$ & - & $\bar{X}$ \\
\hline
\end{tabular}

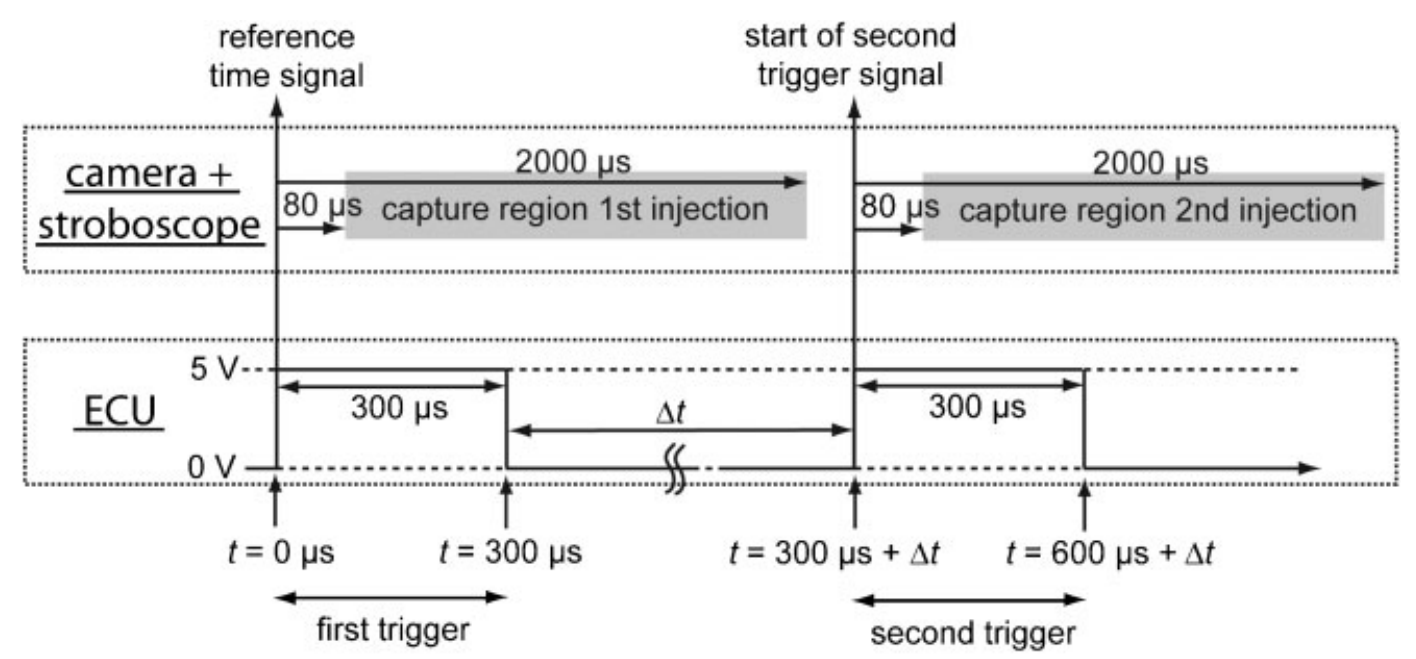

Fig. 4 Trigger scheme of double injection 


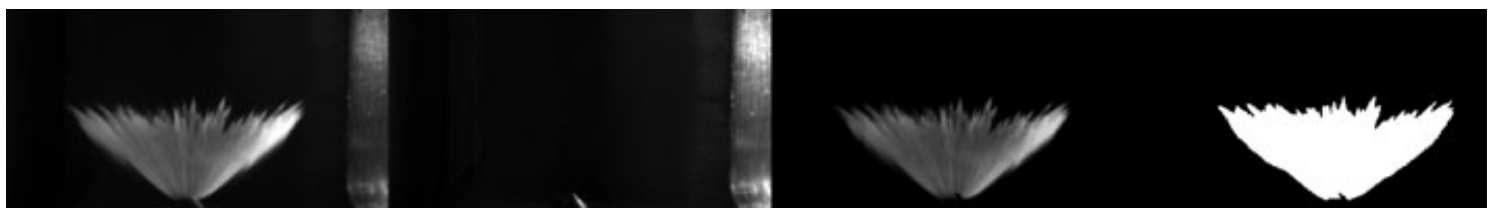

Fig. 5 Automated image processing for single injection (from left to right: original image; background; image with subtracted background; evaluated image)

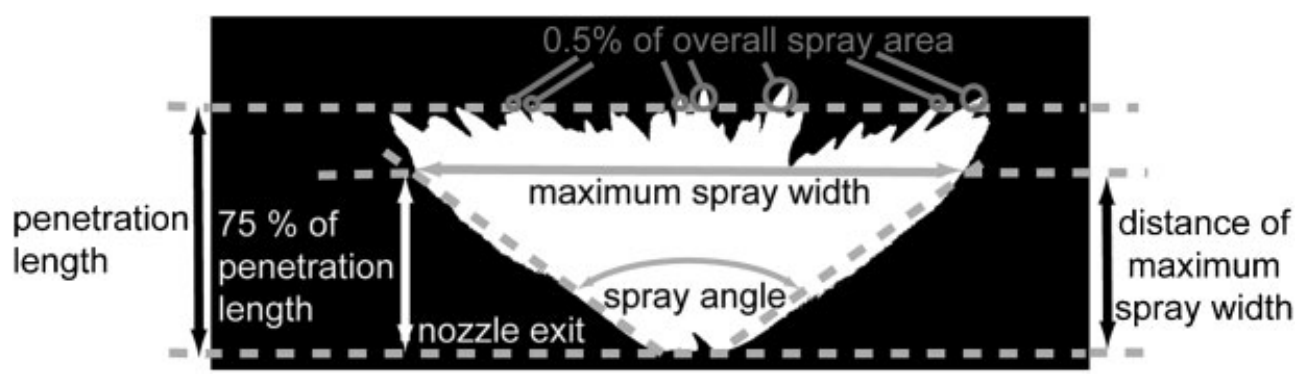

Fig. 6 Evaluated macroscopic quantities

to ensure constant chamber conditions without any residues, yet slow enough not to interfere with the mixture formation process.

\section{DESCRIPTION OF IMAGE PROCESSING}

\subsection{Quantities to be measured and evaluated}

To handle the vast amount of data that is created by visualization measurements, the image processing has been automated using MATLAB routines. First, the images are cleaned from any background artefacts by subtraction of a background image recorded prior to the measurements. After subtracting the previous recorded background, the spray is identified by a specific brightness threshold and binarized, i.e. the spray area is all white and gas phase areas are all black. This process is shown in Fig. 5. The first image (from left to right) is the original as taken from the CCD camera, the second image is the background without spray, the third image is the spray image without background, and the fourth image shows the binary image, which is the input to further evaluation.

In order to describe the spray shape, four different macroscopic properties are defined:

(a) penetration length;

(b) spray angle;

(c) maximum spray width;

(d) the distance of maximum spray width from the nozzle exit.

These properties are illustrated in Fig. 6.
The 'penetration length' is the axial distance from the nozzle to the furthermost droplets. Technically, this length defined in terms of spray area, i.e. 0.5 per cent of the overall spray area, may fall beyond the penetration length. In this way particularly long strings, orphan droplets, and so on are ignored. The 'maximum spray width' describes the maximum width of the full cone, without any interruptions by strings, where the axial distance between the location of maximum spray width and the nozzle is referred to as the 'distance of maximum spray width'. The spray angle evaluated is calculated based on the half spray width at 75 per cent of the penetration length.

In addition to the five properties introduced earlier, the spray shape and the position of the strings are evaluated with contour plots of the spray shape at given points in time. Figure 7 shows an example of a contour plot at $200 \mu \mathrm{s}, 250 \mu \mathrm{s}, 300 \mu \mathrm{s}, 350 \mu \mathrm{s}, 400 \mu \mathrm{s}$, and $450 \mu$ s after energizing the injector. These contours belong to the spray images shown in Fig. 8 .

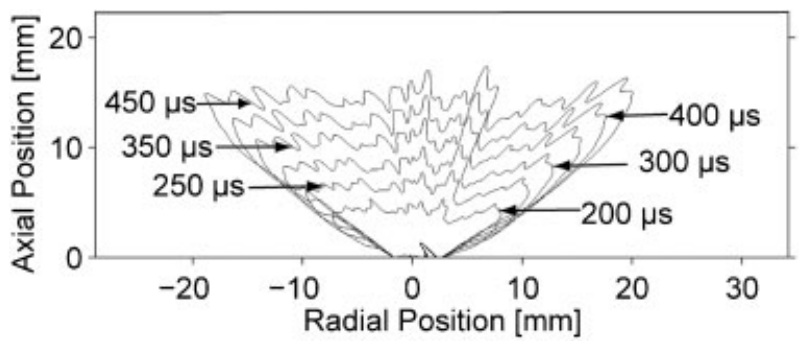

Fig. 7 Contour plot for $200 \mu$ s to $450 \mu$ s after start of energizing the injector 


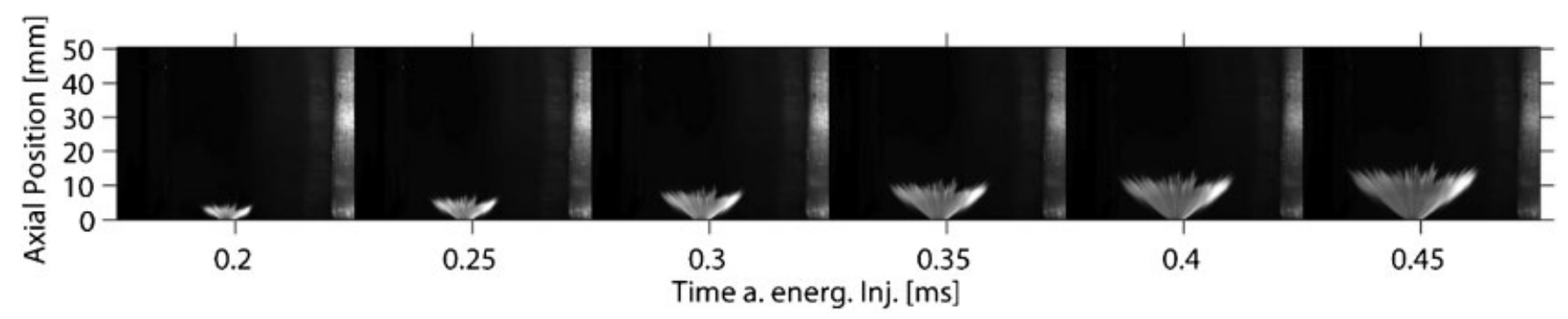

Fig. 8 Series of averaged spray images

\subsection{Modifications for double injection}

For the evaluation of double injections, two different routines are applied. First, the images of the double injection are evaluated with the original approach described before. Once the spray of the first and second injections merge, the sprays generated cannot be distinguished any longer, as shown in Fig. 9. From then on, only the influence of the second injection on the penetration length of the first injection is analysed.

While the first (original) approach gives information on the first injection only, the second (modified) approach aims at evaluating the properties of the second injection. To compare these with the ones from a single injection, the residues of the first injection must be erased from the original image. Therefore, the capture of a single injection taken at the same point in time is subtracted (rather than a plain background image), making the first injection disappear. Figure 10 gives an example of the underlying process.
Owing to the scattered light visualization technique, the light is distributed non-uniformly across the full cone. The routine described previously does not work on the 'bright' side of the spray, which is directly exposed to the stroboscope light. Therefore, only the 'dark' side of the spray cone is investigated. Here, the first and second injections are distinguishable; however, the image processing may corrupt the shape of the second injection. Therefore, only the penetration length will be investigated exemplarily with the method described earlier, as it is marginally affected by this problem.

\section{RESULTS AND DISCUSSION}

\subsection{General spray properties}

For both single and double injections, the first fuel becomes visible about $100-140 \mu$ s after energizing the injector; injector closing occurs between 500 and $550 \mu \mathrm{s}$. The formation of the characteristic side

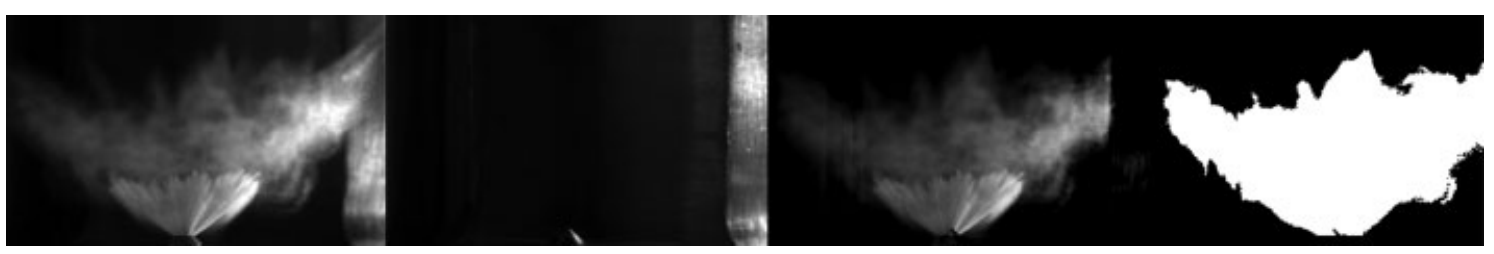

Fig. 9 Automated image processing developed for single injection applied for double injection

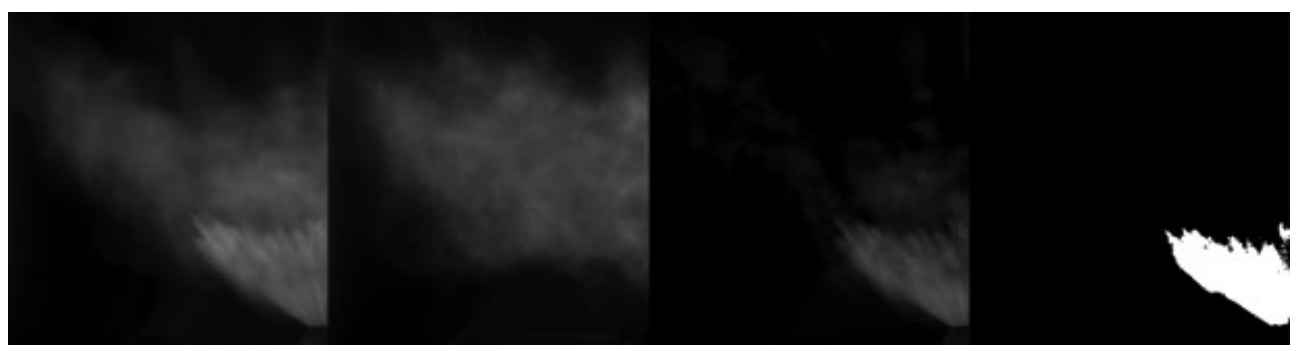

Fig. 10 Automated image processing developed for double injection (from left to right: original image of double injection; background with first injection; image with subtracted background; evaluated image) 
vortex starts at about $600 \mu \mathrm{s}$. These timings are independent of the chamber conditions. Unless stated differently, all future timing indications will be related to the energizing signal as well.

When interpreting visualization images, it has to be noted that all images shown are averaged over 20 shots. It turns out that the piezo-injectors offer outstanding repeatability in shape and timing. Figure 11 shows a single injection at two different points in time, $400 \mu \mathrm{s}$ and $700 \mu \mathrm{s}$. At $400 \mu \mathrm{s}$, the strings and the border of the spray show a sharp contrast, which is evidence for low deviation of the spray shape from one injection to the next. At $700 \mu \mathrm{s}$, the nozzle closes and the spray diffuses, the strings are evaporating, and eddies are formed, as shown in Fig. 11. At this time after energizing the injector, the spray patterns start differing from each other, resulting in blurred average images.

\subsection{Spray geometry at single injection}

For a first overview of the atomization and evaporation process, the geometry of the spray will be evaluated based on the geometric properties derived earlier. The processing of the geometry is carried out using single shots, not with averaged images. In addition to the mean geometry error bars are plotted, which give an indication of the spray repeatability at the specific point in time.

The penetration length and the distance of maximum spray width evolve in a very similar way. Both quantities follow a steep linear increase until $600 \mu \mathrm{s}$. After $650 \mu$ s the slopes of both the penetration length and the distance of maximum spray width flatten, each approaching a constant value. The pressure variation reveals that an increase in chamber pressure results in a shorter spray over the entire spray lifetime. Figure 12 shows clearly the result of such a pressure variation at $500 \mathrm{~K}$.

The influence of the chamber temperature on the penetration length and on the distance of maximum spray width is relatively small when compared to the pressure effect. Differences can be observed only after closing the nozzle. Higher temperatures and thus lower gas densities lead to a gentle increase in penetration length (Fig. 13). Another temperature influence can be observed towards the end of the injection, where the spray evaporates earlier within a high-temperature atmosphere. Owing to the fast evaporation, the penetration length and the distance of maximum spray width can hardly be detected, resulting in a higher standard deviation at the end of the evaluation interval, as shown in Fig. 14.

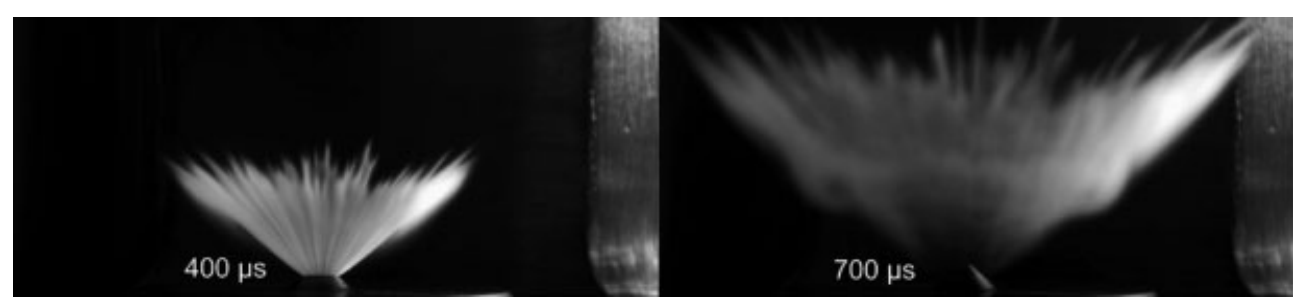

Fig. 11 Averaged images for open (left) and closed nozzle (right) conditions
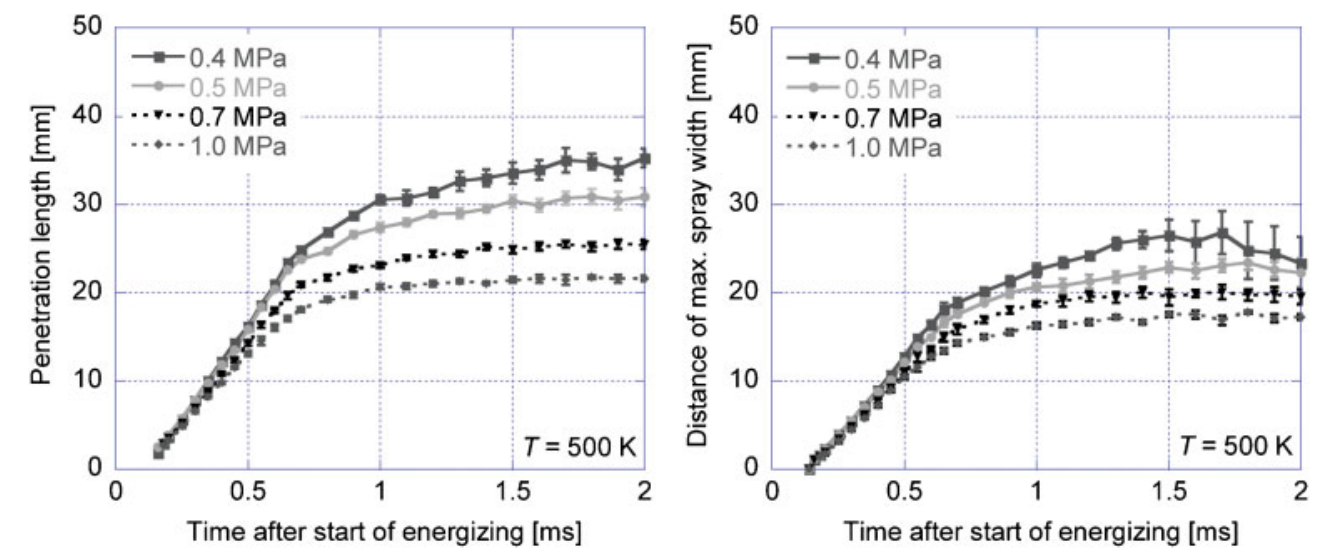

Fig. 12 Evaluation of penetration length and distance of maximum spray width for a chamber pressure variation 

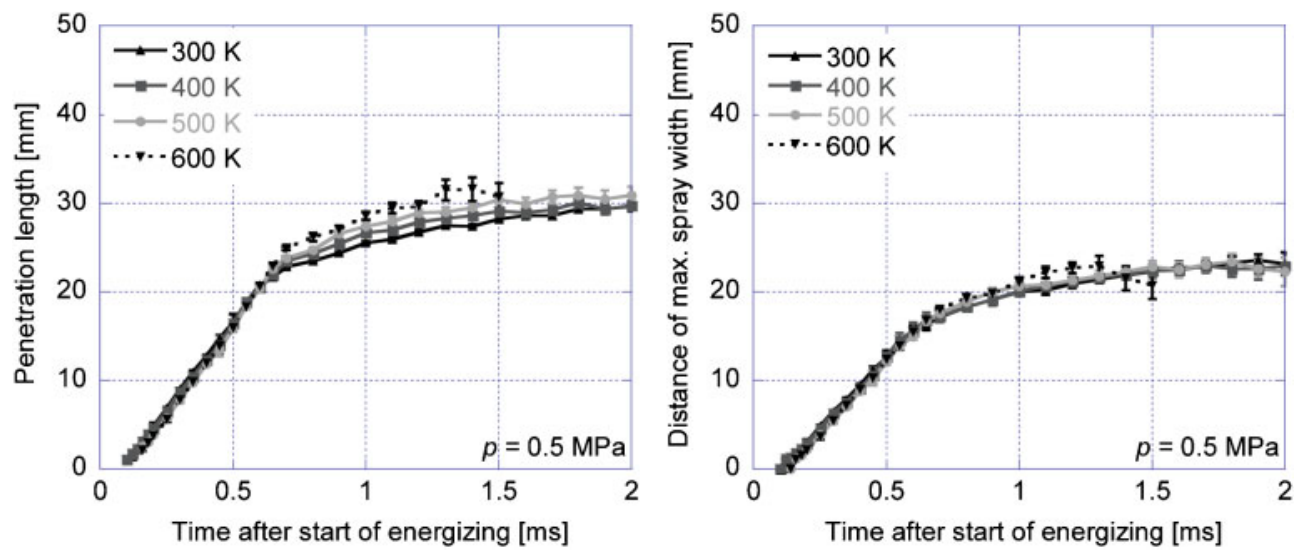

Fig. 13 Evaluation of penetration length and distance of maximum spray width for a chamber temperature variation
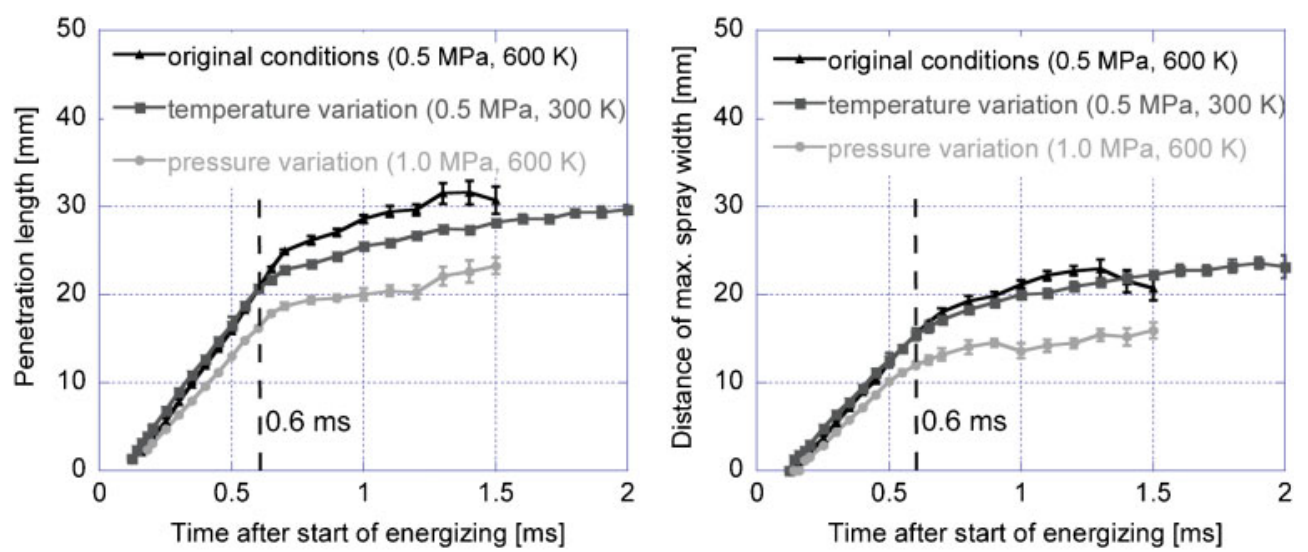

Fig. 14 Evaluation of penetration length and distance of maximum spray width for doubled chamber density

When comparing the influence of gas phase temperature, pressure, and density on the penetration length and distance of maximum spray width, it is concluded that the chamber pressure influences the spray preferably during the first time interval up to $600 \mu \mathrm{s}$, when fresh fuel is delivered by the open nozzle to the spray. After closing the nozzle, the density influences the penetration process additionally. This can be seen in Fig. 14. Here, the penetration length and the distance of maximum spray width are compared for a pressure and a temperature variation. Both variations double the density of the gas phase.

Evaluating the spray angle, the determination of the spray angle value is inaccurate at very short penetration lengths because of the great influence of small changes in the spray half width. Furthermore, the spray angle is only reasonable for an open nozzle. Therefore, it will be evaluated from $300 \mu$ s to $500 \mu$ s only. Different variations in chamber condi- tions reveal that there is no measurable pressure, density, or temperature influence on the spray angle, as shown in Fig. 15. Thus the spray angle defined at 75 per cent of the penetration length is independent of ambient conditions.

Owing to the constant spray angle, the maximum spray width shows the same progress as the penetration length as long as the nozzle is open. However, in contrast to the penetration length, the maximum spray width is strongly influenced by evaporation once the nozzle is closed, i.e. when the spray cone starts narrowing. For times up to $900 \mu \mathrm{s}$ the curves continue as if the nozzle was still open. At later times, the maximum spray width increases slowly at low temperatures or decreases quickly owing to evaporation at higher temperatures.

Figure 16 shows a temperature variation (left) and a pressure variation (right) of the maximum spray width. For the low-temperature cases at $300 \mathrm{~K}$ and $400 \mathrm{~K}$, the results show almost no decrease in maxi- 


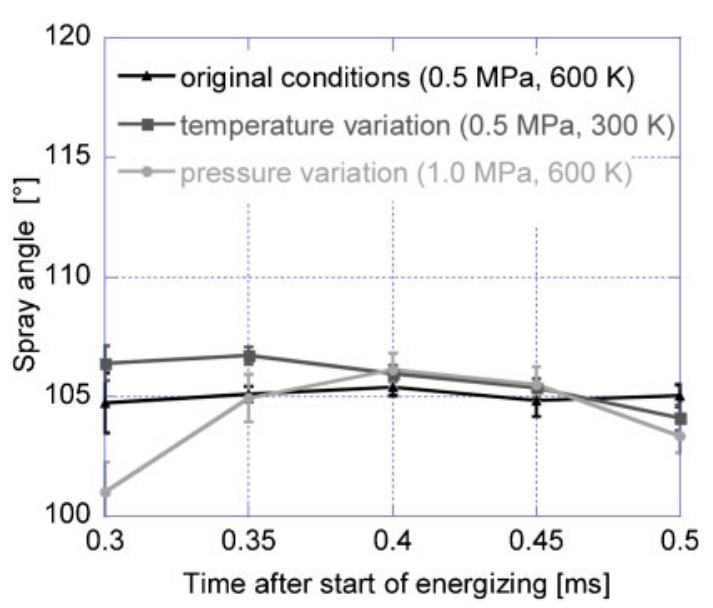

Fig. 15 Evaluation of the spray angle for doubled chamber density

mum spray width. Evaporation occurs once the temperature of $450 \mathrm{~K}$ is exceeded, leading to the decrease in spray width mentioned before. Furthermore, Fig. 16 (right) proves that there is a strong pressure effect on the maximum spray width, particularly towards the end of the injection.

\subsection{Spray structure at single injection}

The investigation of the spray structure is based on the contour plots introduced before and on averaged images. The influence of pressure and temperature on the string distribution has to be analysed within the time interval from 200 to $450 \mu \mathrm{s}$. After $450 \mu \mathrm{s}$, the evaluation focuses on the location and the spatial extension of the side vortex.

Figure 17 shows a comparison of the string shapes for different temperature and pressure conditions at 200,250 , and $300 \mu \mathrm{s}$. The contour plots reveal that the strings and the gaps move in parallel, indicating a uniform velocity distribution over the circumference of the spray cone regardless of the chamber conditions. However, it turns out that a temperature increment somewhat straightens some of the smaller strings. The effect becomes visible first at temperatures beyond $450 \mathrm{~K}$, as shown in Fig. 17 comparing the string shapes for $300 \mathrm{~K}$ and $500 \mathrm{~K}$. In contrast, any variation in chamber pressure decreases the penetration length, leading to a slight compression of the string structure. Besides the penetration effect, the string shape and location are nearly independent
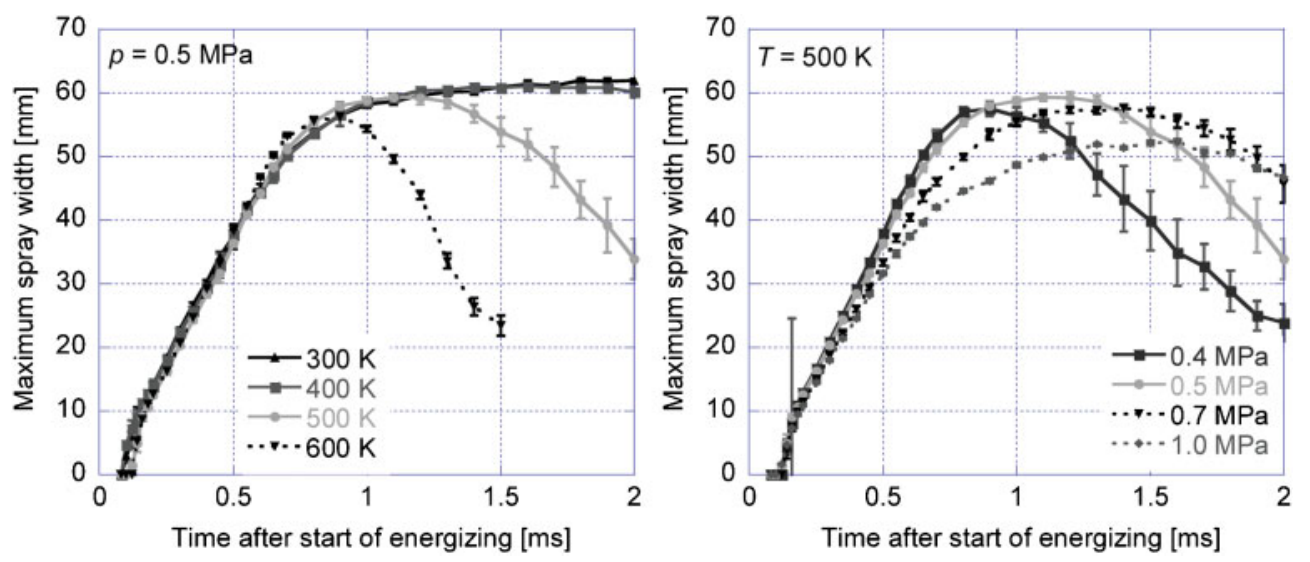

Fig. 16 Evaluation of maximum spray width for a temperature variation (left) and a pressure variation (right)

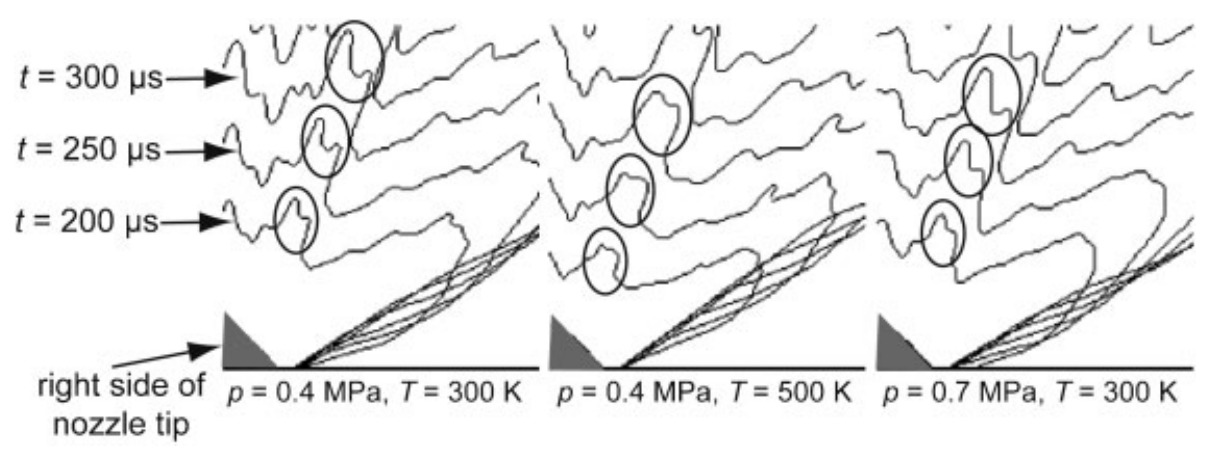

Fig. 17 Changes in spray contour $200 \mu$ s to $300 \mu$ s after start of injection 
of the pressure for the investigated pressure range (Fig. 17). The reasons for the comparably large temperature effect and the de-facto pressure independency will be the subject of future investigations.

In addition to the string properties, the contour plots and the single images also give information about the location and appearance of the recirculation eddies outside the cone. Regardless of the chamber conditions, these eddies are formed after $600 \mu$ s. The eddy shape depends on the chamber pressure and density. In analogy to the penetration length, the eddy is found closer to the nozzle when chamber pressure and density are increased. Owing to high evaporation rates and low aerodynamic forces, the eddy size is smaller at low pressures and high temperatures, as Fig. 18 suggests.

After the nozzle has been closed, the distance of the eddy from the nozzle is characteristic for the chamber conditions. Owing to the reduction in penetration velocity after closing the nozzle and because of the strong recirculation, the liquid fuel at the eddy position can be detected for the entire spray lifetime (see Fig. 19). After $600 \mu$ s only the eddy width and spray width increase any further, as more and more liquid fuel is sucked into the recirculation zone. The eddy position remains constant.

\subsection{Penetration length at double injections: investigation of the second injection only}

As described before, there are some limitations when filtering the artefacts of the first injection from the double injection images. The second injection may only be extracted within a short time slot after the second injection has been energized. These time slots are listed in Table 2 for various chamber conditions. The time refers to the start of the second trigger signal (see Fig. 4).

For high-temperature conditions (beyond $500 \mathrm{~K}$ ), the second injection is not influenced by the first injection once the injection interval exceeds $\Delta t=400 \mu \mathrm{s}$. Therefore, the threshold at $\Delta t=400 \mu \mathrm{s}$ is further investigated. The results shown in Fig. 20 (left) reveal a decrease in penetration length for the second injection, which is almost independent of the chamber pressure. The reduction is most probably caused by the higher gas
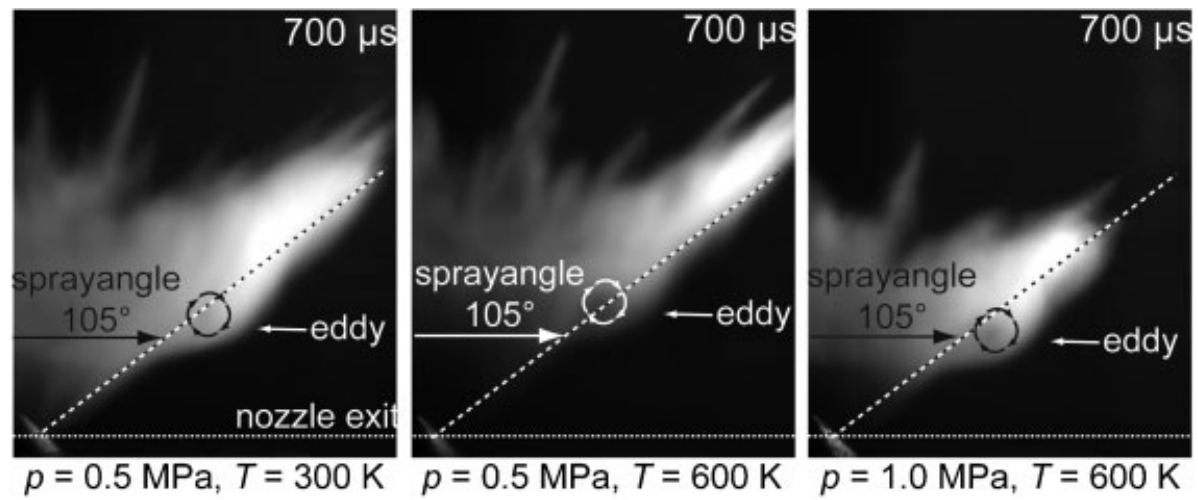

Fig. 18 Single images of the spray at $700 \mu$ s after energizing the injector
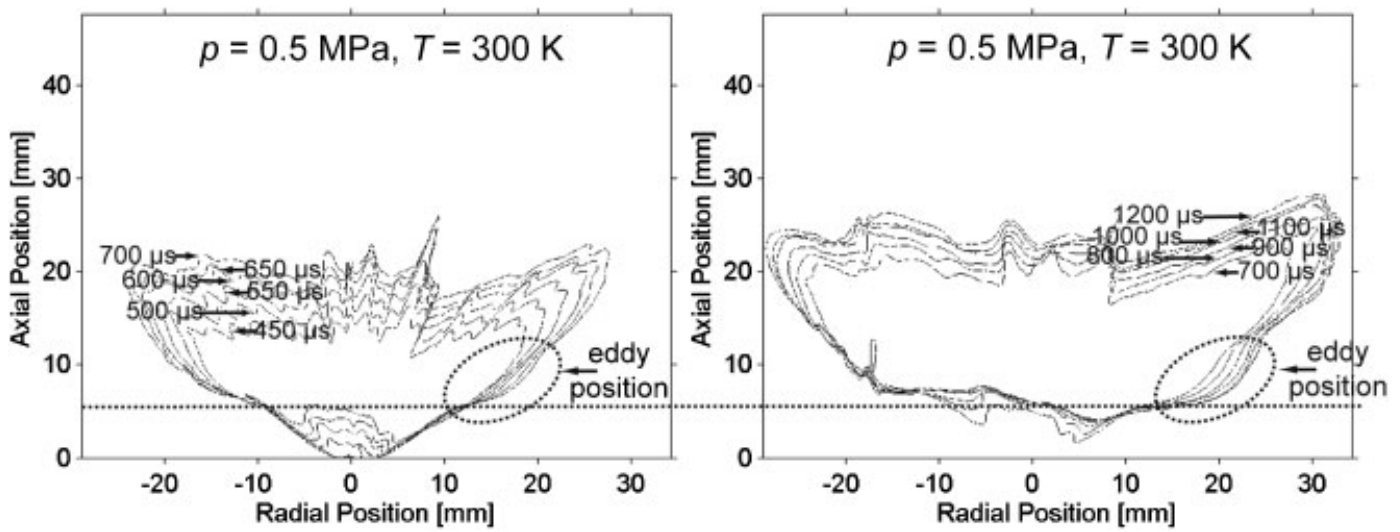

Fig. 19 Contour plots at $0.5 \mathrm{MPa}, 300 \mathrm{~K}$ for 450 to $700 \mu$ s (left) and 700 to $1200 \mu$ s after energizing the injector (right) 
Table 2 Separation of the first and second injection could be applied at the listed time gaps

\begin{tabular}{ll}
\hline $\begin{array}{l}\text { Conditions of the air in } \\
\text { the pressure chamber }\end{array}$ & $\begin{array}{l}\text { Time gaps for separate investigation } \\
\text { of the second injection event }\end{array}$ \\
\hline$p=0.3 \mathrm{MPa}, T=300 \mathrm{~K}$ & All at $\Delta t: 140-700 \mu \mathrm{s}$ \\
$p=0.5 \mathrm{MPa}, T=300 \mathrm{~K}$ & $\Delta t \leqslant 600 \mu \mathrm{s}: 140-400 \mu \mathrm{s}$ \\
& $\Delta t>600 \mu \mathrm{s}: 140-700 \mu \mathrm{s}$ \\
$p=0.5 \mathrm{MPa}, T=500 \mathrm{~K}$ & $\Delta t \leqslant 600 \mu \mathrm{s}: 140-800 \mu \mathrm{s}$ \\
& $\Delta t>600 \mu \mathrm{s}: 140-1000 \mu \mathrm{s}$ \\
$p=0.5 \mathrm{MPa}, T=600 \mathrm{~K}$ & All at $\Delta t: 140-900 \mu \mathrm{s}$ \\
$p=1.0 \mathrm{MPa}, T=500 \mathrm{~K}$ & $\Delta t \leqslant 1000 \mu \mathrm{s}: 140-800 \mu \mathrm{s}$ \\
& $\Delta t>1000 \mu \mathrm{s}: 140-1000 \mu \mathrm{s}$ \\
\hline
\end{tabular}

phase density due to cooling and evaporation, and by collision events between the first and second injections. The temperature variation shown in Fig. 20 (right) indicates less spray-spray interaction at high temperatures, where the decrease in penetration length is less distinct.

At low-temperature conditions, the penetration reduction is independent of the injection interval, even if it is extended from $\Delta t=400 \mu \mathrm{s}$ to $3200 \mu \mathrm{s}$ to repress spray-spray interaction (Fig. 21, left). The reason for the time independency may be the long spray lifetime due to low evaporation rates at lowtemperature conditions. According to Fig. 21 (right) at $0.5 \mathrm{MPa}, 300 \mathrm{~K}$ the spray cone is still visible even $2000 \mu$ s after energizing the single injection.

\subsection{Penetration length at double injections: investigation of the spray after first and second injections}

The penetration length of both injection events potentially gives a good indication of whether or not the first injection is pushed forward by the following injection. This is particularly interesting for control purposes, as it would allow manipulation of the first injection subsequently, i.e. after the first needle lift has already been finished. The effect of double injections is evaluated for various pressures and temperatures as described previously.
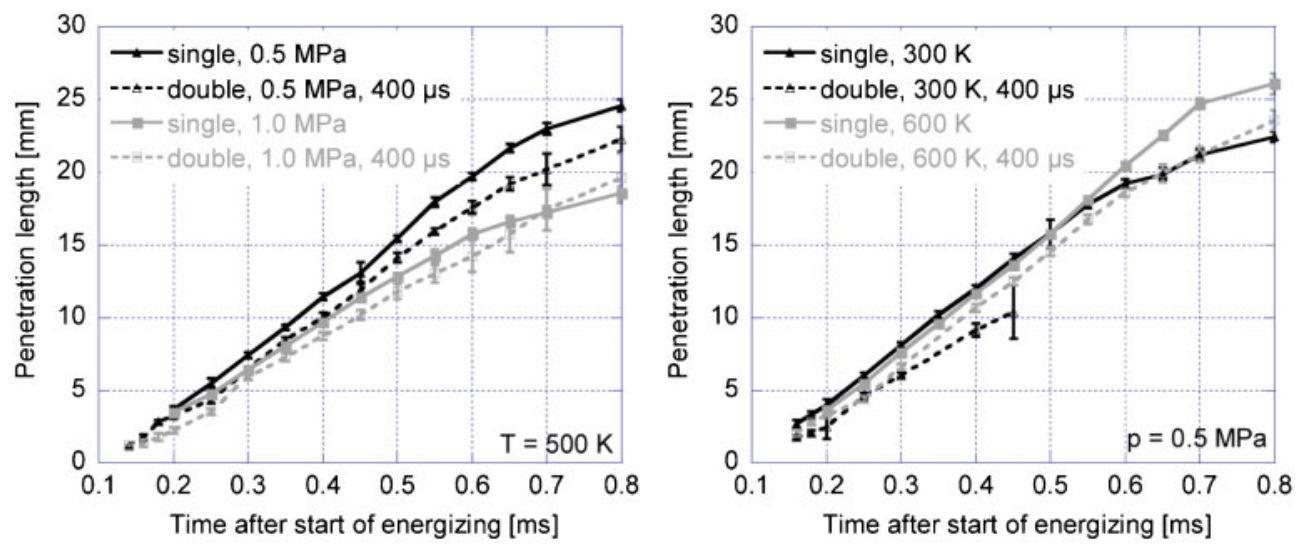

Fig. 20 Comparison of penetration of the single injection to the second injection of the double injection at $\Delta t=400 \mu$ s (left: pressure variation; right: temperature variation)
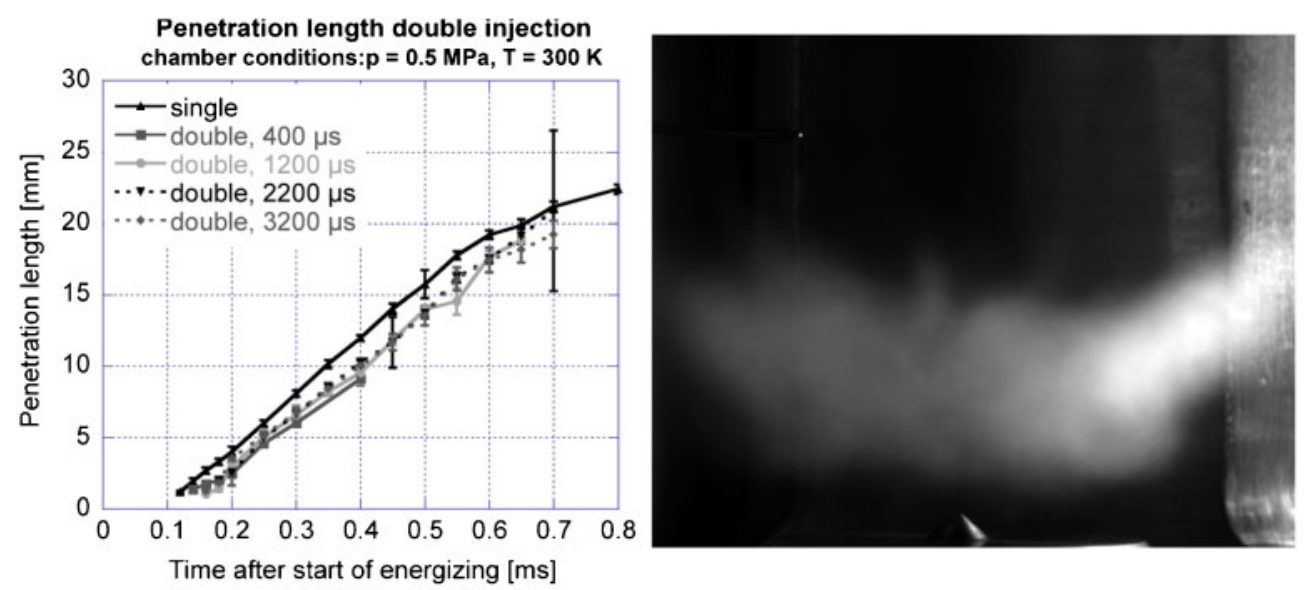

Fig. 21 Penetration at $0.5 \mathrm{MPa}$ and $300 \mathrm{~K}$ (left: comparison of different $\Delta t$; right: $2000 \mu \mathrm{s}$ after energizing for single injection) 

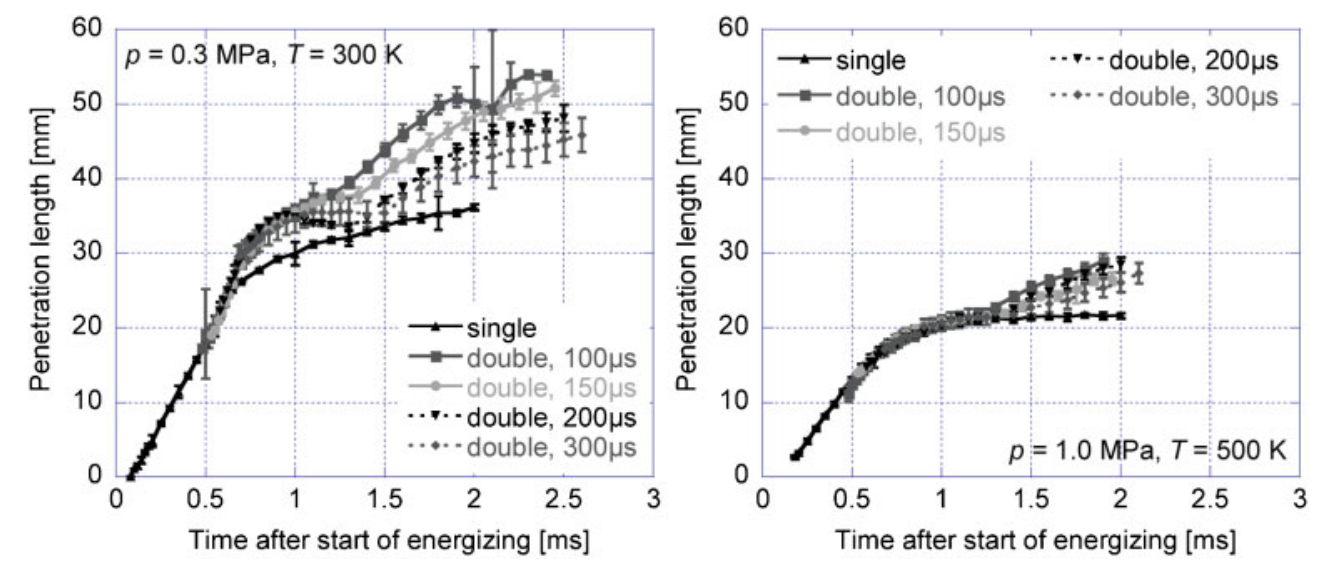

Fig. 22 Penetration length of both injections for $0.3 \mathrm{MPa}, 300 \mathrm{~K}$ (left) and $1.0 \mathrm{MPa}, 500 \mathrm{~K}$ (right)

For short injection intervals of $\Delta t=100 \mu \mathrm{s}$, the needle does not close in between the injections. However, the penetration length does not show a linear behaviour as observed with single injections, but slows down at $500 \mu$ s due to needle movement. For low-pressure and low-temperature conditions $(0.3 \mathrm{MPa}, 300 \mathrm{~K})$, the penetration length will exceed the single injection after $700 \mu \mathrm{s}$ (Fig. 22, left). At high-pressure and high-temperature conditions ( $1 \mathrm{MPa}, 500 \mathrm{~K}$ ), the increase in penetration becomes visible after $1400 \mu$ s (Fig. 22, right). In both cases, the penetration grows to about 150 per cent of the single injection penetration. The increase is basically caused by the additional fuel involved.

Increasing the injection interval $\Delta t$ the penetration length flattens, i.e. the influence of the second injection is reduced, which is clearly visible when extending $\Delta t$ from 100 to $300 \mu$ s. At low-temperature conditions, the penetration length of the first injection does not differ from a single injection once $\Delta t$ exceeds $1000 \mu \mathrm{s}$. At high-temperature conditions, the threshold is $\Delta t=800 \mu \mathrm{s}$ only, which is due to the high evaporation rate, making the first spray disappear earlier. This means that the first injection can only be influenced subsequently by another injection if the injection interval chosen is small enough.

\subsection{Evaluation of the spray structure details at double injections}

When analysing the spray structure details, it must be borne in mind that double injections cannot be compared with a single injection, as the injector position has been changed slightly since the measurement set-up was dismounted in between the measurement campaigns. For comparison purposes it is assumed that at long injection intervals of $\Delta t=3700 \mu \mathrm{s}$, the second injection is almost identical

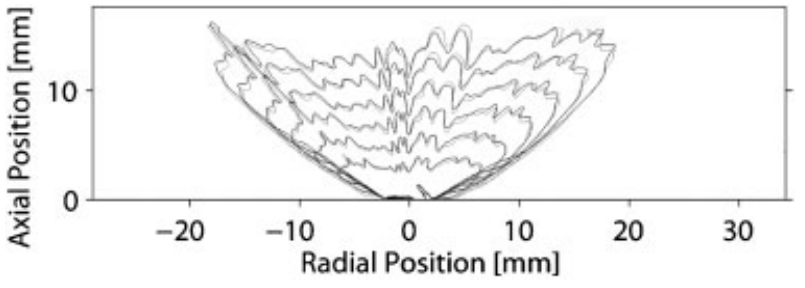

Fig. 23 Comparison of the contour plots at $0.3 \mathrm{MPa}$, $300 \mathrm{~K}$, between 200 and $450 \mu$ s for single injection (black line) and second injection of double injection with $\Delta t=3700 \mu$ s (grey line)

to a single injection, at least in terms of the spray structure details, i.e. at the beginning of the injection. This assumption is backed by Fig. 23, which does not show any differences between single injection and second injection for double injection at $\Delta t=3700 \mu \mathrm{s}$. Therefore, the second injection at $\Delta t=3700 \mu \mathrm{s}$ is a valid basis for further comparisons.

At the very beginning of the injection and at lowtemperature $(300 \mathrm{~K})$ and low-pressure $(0.3 \mathrm{MPa})$ conditions, any reduction of the injection interval below $\Delta t=800 \mu \mathrm{s}$ will change the shape of strings that run ahead of the spray (see Fig. 24). At long injection intervals $\Delta t$ and at increased ambient pressure this phenomenon can no longer be observed.

Another impact of the injection interval can be found clearly when comparing the spray structure after $250 \mu$ s at chamber conditions of $0.5 \mathrm{MPa}$ and $600 \mathrm{~K}$. Figure 25 shows single images for different injection intervals $\Delta t$ at the conditions stated previously. When decreasing the injection interval $\Delta t$ from 3700 to $2700 \mu$ s, there are no visible differences in the string distribution. A further decrease of the injection interval causes small variations in the string shape that become more visible once the injection interval is further reduced. 

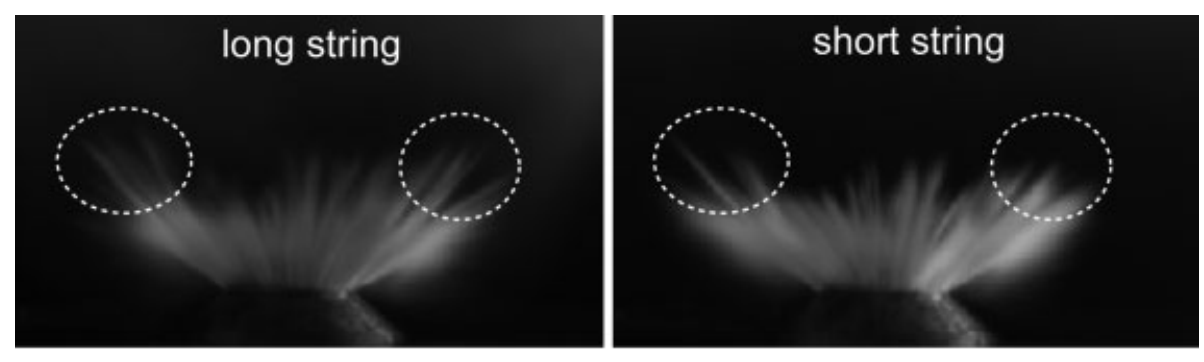

$p=0.3 \mathrm{MPa}, T=300 \mathrm{~K}, \Delta t=600 \mu \mathrm{s} \quad p=0.3 \mathrm{MPa}, T=300 \mathrm{~K}, \Delta t=2200 \mu \mathrm{s}$

Fig. 24 Comparison of strings at $200 \mu$ s after second energizing of the injection using double injection with different $\Delta t$ values

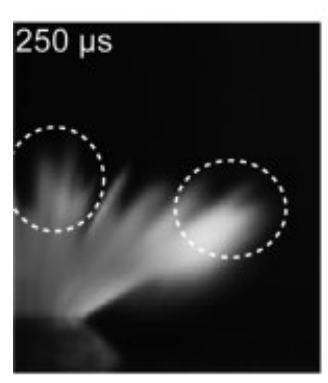

double, $\Delta t=3700 \mu \mathrm{s}$

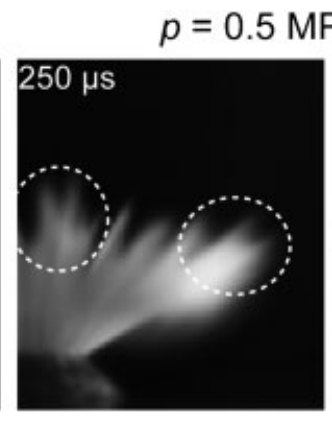

double, $\Delta t=2700 \mu \mathrm{s}$

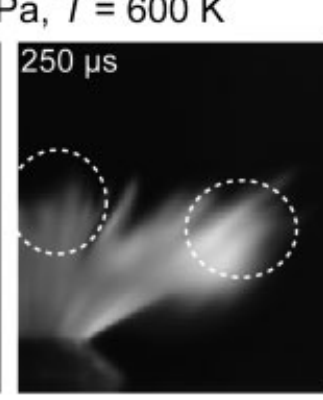

double, $\Delta t=1200 \mu \mathrm{s}$

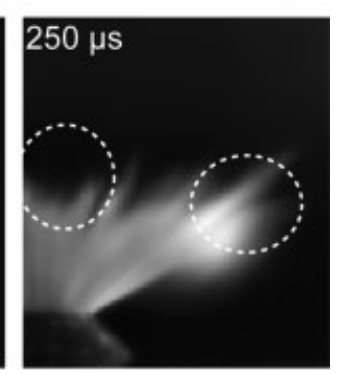

double, $\Delta t=400 \mu \mathrm{s}$

Fig. 25 Spray images at $250 \mu$ s after second energizing of the injection at $0.5 \mathrm{MPa}, 600 \mathrm{~K}$

\subsection{Evaluation of eddy formation at double injections}

As described previously, eddy formation is crucial to the ignition. Therefore, the influence of double injection on eddy formation will be investigated in detail. As found with single injections, the eddy size and the liquid spray density in the recirculation region are dependent on chamber conditions. Even if first small droplets are shed off the spray earlier, the eddy is formed initially after $600-650 \mu$ s. When investigating the eddy with the focus on the influence of double injections, another dependency besides chamber conditions is observed. At low-temperature conditions of $300 \mathrm{~K}$, a change in eddy shape can be detected for double injections even at large injection intervals of $\Delta t=3700 \mu \mathrm{s}$. At shorter injection intervals this influence becomes more evident (comparing the eddy position relative to the spray angle in Fig. 26).

At high-temperature conditions, the impact on eddy shape is visible at short injection intervals only (e.g. for $\Delta t=400 \mu \mathrm{s}$ ), regardless of the chamber pressure (Fig. 27). This may be due to increased evaporation easing spray-spray interaction, or due to lower gas phase densities.

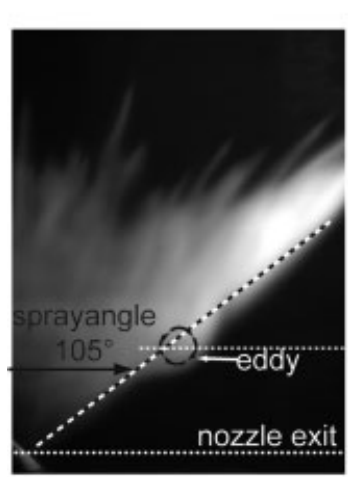

single

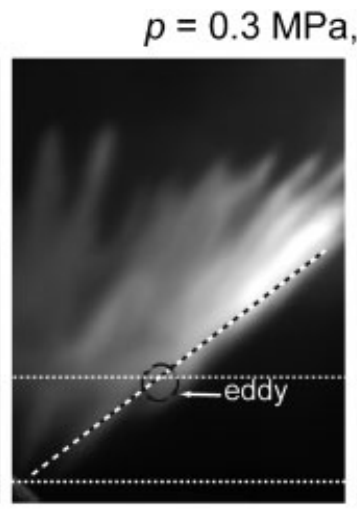

double, $\Delta t=3700 \mu \mathrm{s}$

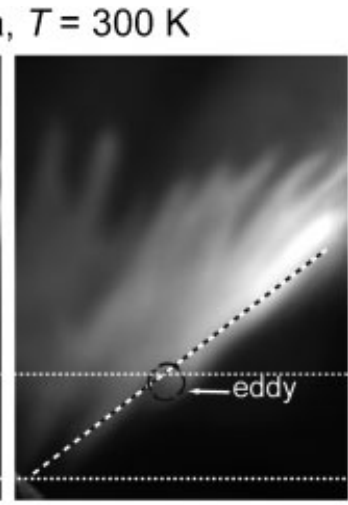

double, $\Delta t=1200 \mu \mathrm{s}$

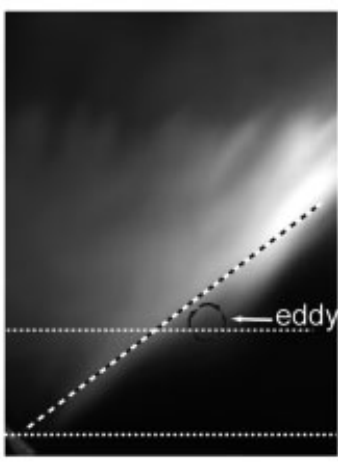

double, $\Delta t=400 \mu \mathrm{s}$

Fig. 26 Single images $700 \mu$ s after energizing injection at $0.3 \mathrm{MPa}, 300 \mathrm{~K}$ 


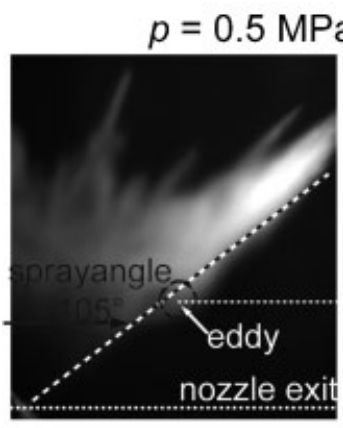

single

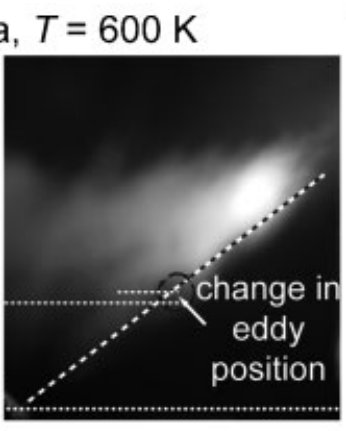

double, $\Delta t=400 \mu \mathrm{s}$

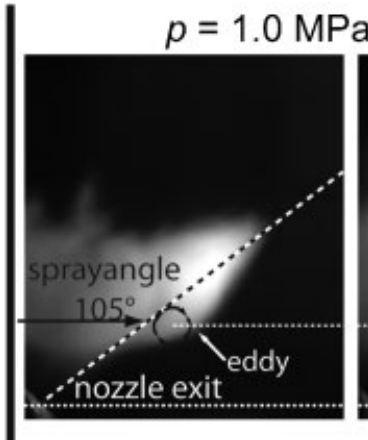

single

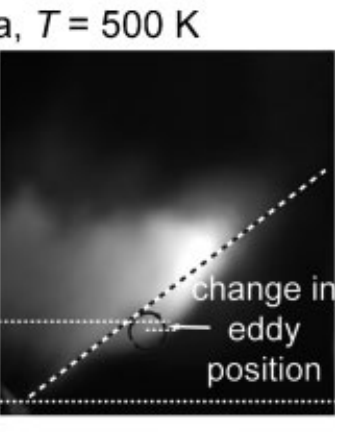

double, $\Delta t=400 \mu \mathrm{s}$

Fig. 27 Single images $700 \mu$ s after energizing injection at $0.5 \mathrm{MPa}, 600 \mathrm{~K}$ and $1.0 \mathrm{MPa}, 500 \mathrm{~K}$

An increase in chamber pressure does not reduce the impact of the double injection on eddy shape. The investigations show that the temperature influences the impact of the double injection on eddy shape more than the pressure.

\section{CONCLUSIONS AND OUTLOOK}

The aim of the current research project is the stabilization of low-temperature combustion by control of the mixture formation process. This may be achieved by a series of short injections during the compression stroke. Therefore, visualization measurements are intended to describe the spray-spray interaction of two consecutive injection events. For the measurements a Continental piezo-injector is utilized.

The investigation of single injections shows that all significant length scales (i.e. the penetration length, maximum spray width, etc.) follow a steep rise with linear slope as long as the nozzle is open. After closing the nozzle, the curves flatten and approach a constant value. It turns out that an increase in chamber pressure will reduce the dimensions of the spray cone. The influence of the chamber temperature is small when compared to that of the chamber pressure. The change in gas phase density induced by temperature changes has an impact on the penetration length towards the end of the injection after the nozzle has been closed. The chamber temperature influences only the spray width, which is visibly reduced for temperatures beyond $450 \mathrm{~K}$ due to evaporation.

The influence of chamber conditions on the details of the spray structure was investigated separately. This structure mainly consists of strings with gaps in between. First, it must be pointed out that the strings and the gaps between the strings move forward with the same velocity. The influence of the rise in chamber pressure on the strings is small. However, when the ambient temperature is increased above $500 \mathrm{~K}$ a great impact on the strings can be observed. The investigation of the recirculation eddy shows only a small dependency on the ambient pressure and density. With increased pressure and density, the centre of the eddy is slightly shifted towards the nozzle exit. In addition, the eddy seems to be stronger with increasing ambient pressure. The axial position of the eddy at $50-100 \mu$ s after closing the nozzle is very characteristic of the hollow cone spray. At that position the spray can be detected until the mixture has nearly evaporated.

When investigating the double injection, three issues must be considered: the influence of the first injection on the second injection, the influence of the second injection on the first injection, and the changes in nozzle exit conditions for double injections.

Influenced by the first injection event, the penetration length of the second injection event decreases. A reason for the decrease may be either the higher ambient density caused by the enrichment with evaporated fuel or collision events between the spray of the second injection and fuel droplets of the first injection. The eddy position of the second injection event is influenced more by the spray of the first injection event if the distance between the two injection events of the double injection or the ambient temperature is decreased.

The impact of the second injection on the spray of the first injection shows a clear dependency on the ambient temperature. For injection intervals higher $\Delta t=1000 \mu \mathrm{s}$, no influence of the second injection on the spray of the first injection can be detected.

For small time differences between two injections (smaller than $800 \mu \mathrm{s}$ ) and only for the low-ambientpressure conditions, the strings look different from 
the strings of the single injection for the time of 180 $250 \mu \mathrm{s}$ after energizing. The investigations on the recirculation eddy show a clear influence of the double injection on eddy shape only for low temperatures or small injection intervals $\Delta t$.

The experimental results described give a good overview regarding the possibility of influencing the injected spray by choosing different ambient conditions or applying double injection. However, there are still two questions to be answered in detail. First, the origin of the strings is still not entirely understood. Therefore, with the knowledge gained so far it cannot be explained why the ambient temperature has an impact on string formation, in contrast to the ambient pressure. The second phenomenon which is not clarified so far is the influence of the double injection on the recirculation eddy. A stronger impact of the double injection on eddy position and shape can be observed for low temperatures. The differences in the spray shape may be due to the higher fuel concentration from the evaporated spray of the first injection or the air flow induced by the first injection. In order to clarify this question computational fluid dynamics simulations could be used in future investigations.

\section{ACKNOWLEDGEMENTS}

It is acknowledged that parts of this study have been achieved within the Collaborative Research Centre 686 (SFB686) study 'Model-based control of homogenized low-temperature combustion', which is funded by the German Research Foundation (DFG). Additionally, the authors would like to thank Continental for providing the injector and drivers required.

(C) Authors 2010

\section{REFERENCES}

1 Zigan, L., Schmitz, I., Flügel, A., Wensing, M., and Leipertz, A. Influence of fuel properties on spray formation and evaporation measured on a piezoelectric injector for the 2nd generation gasoline direct injection. In Proceedings of the Conference on Injection systems for IC engines, Institution of Mechanical Engineers, London, 13-14 May 2009 (Chandos Publishing, Oxford).

2 Schwarz, C., Missy, S., Steyer, H., Durst, B., Schünemann, E., Kern, W., and Witt, A. Die neuen Vier- und Sechszylinder-Ottomotoren von BMW mit Schichtbrennverfahren. MTZ, 2007, May.

3 Béard, P. Modelling of piezo-electric injection in a high pressure cell and validation for non-evaporating and evaporating conditions. In Proceedings of ICLASS-2006, Kyoto, Japan, 27 August-1 September 2006, paper ID ICLASS06-183.

4 Warncke, V., Achleitner, E., and Baecker, $\mathbf{H}$. Development status of the Siemens VDO piezo injection system for spray-guided combustion. In Proceedings of the 27th International Vienna Motor Symposium, Vienna, Austria, 27-28 April 2006.

5 Luttermann, C., Missy, S., Schwarz, C., and Klauer, N. High precision injection in combination with turbocharger of the new BMW twin turbo petrol engine. In Proceedings of the 15th Aachen Colloquium on Automobile and engine technology, Aachen, Germany, 9-11 October 2006.

6 Gavaises, M., Tonini, S., Marchi, A., Theodorakakos, A., Bouris, D., and Matteucci, L. Modelling of internal and near-nozzle flow of a pintle-type outwards-opening gasoline piezo-injector. Int. J. Engine Res., 2006, 7(5), 381-397. DOI: 10.1243/ 14680874JER00306.

7 Reckers, W., Befrui, B., and Corbinelli, G. Investigation of high pressure GDi conical spray atomization for spray-guided combustion systems. In Proceedings of the 8th International Symposium on Combustion diagnostics, Baden-Baden, Germany, 10-11 June 2008.

8 Befrui, B., Corbinelli, G., Robart, D., Reckers, W., and Weller, H. LES simulation of the internal flow and near-field spray structure of an outwardopening GDi injector and comparison with imaging data. SAE paper 2008-01-0137, 2008.

9 Nouri, J. M., Hamid, M. A., Abo-Serie, E., Marchi, A., Mitrolouglou, N., and Arcoumanis, C. Internal and near nozzle flow characteristics in an enlarged model of an outward opening pintle-type gasoline injector. Proceedings of 3rd International Conference on Optical and laser diagnostics, ICOLAD 2007, City University, London, 22-25 May 2007.

10 Nouri, J. M., Hamid, M. A., Yan, Y., and Arcoumanis, C. Spray characterization of a piezo pintletype injector for gasoline direct injection engines. In Proceedings of the 3rd International Conference on Optical and laser diagnostics, ICOLAD 2007, City University, London, 22-25 May 2007.

11 Hermann, A., Krüger, C., Schaupp, U., Arndt, S., Gartung, K., Hübel, M., Spicher, U., and Velji, A. Numerical and diagnostic analysis of the spray propagation and peripheral turbulence of piezo-A injectors and their sensitivity to flow within the injector. In Proceedings of the 8th International Symposium on Combustion diagnostics, BadenBaden, Germany, 10-11 June 2008.

12 Francesco, L., Maranello, R., and Mancini, L. Magneti Marelli outward opening injector spray enhancement through internal flow simulation. In Proceedings of the 8th International Symposium on Combustion diagnostics, Baden-Baden, Germany, 10-11 June 2008.

13 Schmid, A., Lämmle, C., Wright, Y. M., and Boulouchos, K. Sprayuntersuchung in einer Hoch- 
temperatur-Hochdruckzelle. Tagungsband 6. Tagung Diesel- und Benzindirekteinspritzung, Haus der Technik, Germany, 2008.

\section{APPENDIX}

\section{Notation}

$p$

air pressure in the pressure chamber (MPa) air temperature in the pressure chamber $(\mathrm{K})$

time after energizing the injector (s)

injection interval between the first and second injections (s) 